Special Issue of the 6th International Congress \& Exhibition (APMAS2016), Maslak, Istanbul, Turkey, June 1-3, 2016

\title{
Spark Plasma Sintering of Translucent Dy-Y Doped $\alpha$-SiAlON: Study of Sintering Parameters Influence on the Optical Properties by Using Taguchi Method
}

\author{
S. AvCIOGLU ${ }^{a, *}$ AND S. KURAma ${ }^{b}$ \\ ${ }^{a}$ Ondokuz Mayis University, Faculty of Engineering, Department of Materials Science and Engineering, \\ Kurupelit Campus, 55139 Atakum, Samsun, Turkey \\ ${ }^{b}$ Anadolu University, Faculty of Engineering, Department of Materials Science and Engineering, Iki Eylul Campus, \\ 26555, Eskisehir, Turkey
}

\begin{abstract}
The Taguchi approach was applied to optimize optical properties of Dy-Y doped $\alpha$-SiAlON ceramics produced by spark plasma sintering technique. L'16 experimental design was formed according to orthogonal array. Four different levels were used for each parameter (sintering temperature, holding time, pressure and heating rate). After sintering, the densities of the SiAlON ceramics were measured by the Archimedes method in distilled water. The infrared transmittance behavior was investigated in a wave number range of between 4000 and $1000 \mathrm{~cm}^{-1} \mathrm{using}$ the Fourier transform infrared. The microstructure characterizations of the samples were carried out using scanning electron microscopy. Optimal sintering conditions were determined by calculated standard analysis. "Higher-isbetter" approach was followed to calculate standard analysis. The influences of the sintering parameters on the optical properties and densification of Dy-Y doped $\alpha$-SiAlON have been analyzed using analysis of variance. It has been concluded that the sintering temperature had greater influence on the density and transparency of Dy-Y doped $\alpha$-SiAlON ceramics than holding time, pressure and heating rate. Rising sintering temperature to 1850 from $1650^{\circ} \mathrm{C}$, at $20 \mathrm{kN}$ pressure with $90 \mathrm{~s}$ holding time and $50^{\circ} \mathrm{C} /$ min heating rate improved the infrared transmittance $49.32 \%$ for $0.3 \mathrm{~mm}$ sample thickness but higher sintering temperature than $1850^{\circ} \mathrm{C}$ decreased the transparency of the products.
\end{abstract}

DOI: 10.12693/APhysPolA.131.174

PACS/topics: 42.70.Km, 42.70.--a

\section{Introduction}

The glass is most commonly used transparent material. However, for some applications such as lasers, transparent armors, night vision vehicles, high-speed infrared guided missiles, optical amplifiers, electromagnetic (EM) and infrared (IR) windows, traditional glasses chemical, mechanical and thermal properties are not good enough to work at harsh conditions. As an alternative to amorphous transparent materials firstly single crystalline ceramics were developed. The first Nd:yttrium aluminum garnet (YAG) ceramic laser was fabricated in 1995. Currently, rare earth doped YAG is the most extensively studied and widely used for high power lasers. However, YAG is not the best host material for high-power laser operation systems due to its relatively low thermal conductivity and high thermal expansion [1].

Polycrystalline ceramics got involved to the game when better mechanical properties were required for applications like transparent armors. Transparent armor is a material or system of materials designed to be optically transparent, yet to protect from fragmentation or ballistic impacts. They are also used to protect vehicle occupants from hostile conflicts. The primary requirement

*corresponding author; e-mail: suna.avcioglu@omu.edu.tr for a transparent armor system is to not only defeat the designated threat but also to provide a multi-hit capability with minimized distortion of surrounding areas. Three major polycrystalline transparent material candidates currently exist for armor applications: aluminum oxynitride (AlON), magnesium aluminate spinel (spinel), and single crystal aluminum oxide (sapphire).

In contrast to the amorphous materials, when polycrystalline ceramics are taken into consideration, light transmission through polycrystalline material can be understood by adding many different mechanisms. Reflection and absorption based losses are directly related to the microstructure of the polycrystalline material. The main parameters determining the optical features of transparent ceramics are grain size/grain size distribution in the sintered product, phase variety therein, the amount of grain boundary phases, the distribution thereof within the structure and density [2]. To produce new materials that are thinner, lightweight, and offer better ballistic performance microstructure tailoring is an obligation.

SiAlON's are the solid solution of $\mathrm{Si}_{3} \mathrm{~N}_{4}$ with the substitution of $\mathrm{Al}$ and $\mathrm{O}$ for $\mathrm{Si}$ and $\mathrm{N}$. Due to their excellent combination of mechanical strength, toughness, hardness and thermal shock resistance they are commonly used for structural advanced engineering applications [3]. Even though in last recent years their suitability to functional applications such as transparent materials has taken huge interest [4-6]. However, controlling all 
processing parameters to produce translucent SiAlON, including sintering method, sintering temperature, holding time, heating/cooling rates, composition changes and using different kind of dopants to optimization of optical properties of material requires high amount of experimental work and cost. Investigating all of these parameters in a single work may not be possible. In order to investigate the effect of each factor and attain the maximum transmission, an optimization strategy is required to find the best experimental conditions. The Taguchi method is a very useful tool to solve the complex and confusing problems with fewest variables and fewer tests in many areas. It includes the design of an experiment process using orthogonal arrays that allows independent evaluation of factors through a small number of runs. Due to these reasons, in this study, the effect of sintering parameters such as temperature, holding time, heating rate, and pressure on optical properties of SiAlON ceramics was investigated.

\section{Material and method}

In this study Dy and $\mathrm{Y}$ doped composition which lie on the $\mathrm{Si}_{3} \mathrm{~N}_{4}-9 \mathrm{AlN}: \mathrm{Y}_{2} \mathrm{O}_{3}(m=2 n)$ tie line of the $\alpha$ plane in the system of $\mathrm{M}-\mathrm{Si}-\mathrm{Al}-\mathrm{O}-\mathrm{N}(\mathrm{M}=\mathrm{Y}$ or Dy) were prepared according to the formula of $\mathrm{R}_{m / 3} \mathrm{Si}_{12-(m+n)} \mathrm{Al}_{m+n} \mathrm{O}_{n} \mathrm{~N}_{16-n}$. Starting powders of $\alpha-\mathrm{Si}_{3} \mathrm{~N}_{4}$ (UBE-10, containing $1.6 \%$ oxygen), AlN (Tokuyama, containing $1 \%$ oxygen), $\mathrm{Al}_{2} \mathrm{O}_{3}$ (99.99\%, Sumitomo AES IIC), $\mathrm{Y}_{2} \mathrm{O}_{3}\left(99.99 \%\right.$, $\mathrm{HC}$ Starck) and $\mathrm{Dy}_{2} \mathrm{O}_{3}$ (99.99\%, HC Starck) were mixed in ethanol, milled by using $\mathrm{Si}_{3} \mathrm{~N}_{4}$ balls in a $\mathrm{Si}_{3} \mathrm{~N}_{4}$ jar. After milling, the powder slurry was dried at $60^{\circ} \mathrm{C}$ then sieved. A charge of $3.0 \mathrm{~g}$ of powder were placed between two carbon rams in a cylindrical carbon die with an inner diameter of $20 \mathrm{~mm}$, then were sintered under vacuum atmosphere in a spark plasma sintering (SPS) apparatus (FCT GmbH Ltd). The sintered samples were grinded to $0.3 \mathrm{~mm}$ in thickness with the surface perpendicular to the SPS direction for optical transmittance measurements. Bulk densities of sintered specimens were measured by the Archimedes principle. Optical transmissions at wave numbers $4000-1000 \mathrm{~cm}^{-1}$ were measured by the Fourier transform infrared (FTIR) method (Bruker Tensor27). The microstructure characterization of the samples were carried out using scanning electron microscope (Zeiss Supra 50). Taguchi L'16 orthogonal array was applied for the optimization of process parameters to produce Dy$\mathrm{Y}-\alpha-\mathrm{SiAlON}$ ceramics.

In the present work, the transmission and density of the sintered products were selected as the quality character factors to optimize the process control factors. $\mathrm{S} / \mathrm{N}$ ratios were calculated to analyze the influence of control factors (sintering temperature, pressure, holding time, and heating rate) on responses. $\mathrm{S} / \mathrm{N}$ ratio was chosen according to the criterion "higher-is-better" in order to maximize the density and transparency of the ceramics. Minitab software was used for statistical calculations. Control factors and levels for the experimental design were shown in Table I.

TABLE I

Control factors and levels for the experimental design.

\begin{tabular}{c|c|c|c|c|c|c}
\hline \hline Symb. & $\begin{array}{c}\text { Control } \\
\text { factors }\end{array}$ & Unit & Lev. 1 & Lev. 2 & Lev. 3 & Lev. 4 \\
\hline$A$ & $\begin{array}{c}\text { sintering } \\
\text { temperature }\end{array}$ & ${ }^{\circ} \mathrm{C}$ & 1650 & 1750 & 1850 & 1950 \\
$B$ & pressure & $\mathrm{kN}$ & 5 & 10 & 15 & 20 \\
$C$ & holding time & $\mathrm{min}$ & 0.5 & 1.5 & 2.5 & 3.5 \\
$D$ & heating rate & ${ }^{\circ} \mathrm{C} / \mathrm{min}$ & 50 & 100 & 200 & 300
\end{tabular}

\section{Results and discussion}

The resultant density and maximum transmission values for samples with $0.3 \mathrm{~mm}$ thickness are provided in Table II. Also this table includes the used combinations of each factor and levels. For example, $\mathrm{A}_{1} \mathrm{~B}_{1} \mathrm{C}_{1} \mathrm{D}_{1}$ means that at first experiment used sintering parameters are level 1 of all control factors. According to the results maximum density was achieved by using $\mathrm{A}_{3} \mathrm{~B}_{4} \mathrm{C}_{2} \mathrm{D}_{1}$ combination. However, almost $99 \%$ dense products were produced by ten other combinations as well. In the case of $1650{ }^{\circ} \mathrm{C}$ used as sintering temperature $\left(A_{1}\right)$, just one sample could reach its $99 \%$ theoretical density due to the relatively long holding time $(2.5 \mathrm{~min})$ and high pressure $(20 \mathrm{kN})$. When sintering temperature increased to $1750^{\circ} \mathrm{C}$ and holding time to $3.5 \mathrm{~min}, 15 \mathrm{kN}$ pressure could be enough to obtain fully dense sample $\left(\mathrm{A}_{2} \mathrm{~B}_{3} \mathrm{C}_{4} \mathrm{D}_{1}\right)$. Three samples fully densified even at shorter holding times and lower pressure when one level higher sintering temperature $\left(1850^{\circ} \mathrm{C}\right)$ was used. For highest sintering temperature no matter which combination of other factors was used all samples could successfully have densified. These observations show that sintering temperature is the most dominant factor which affects densification behavior of SiAlON ceramics. In order to investigate importance of factors, analysis of variance (ANOVA) were carried out by using Minitab software.

The results of ANOVA analysis for density of products are given in Table III. It is clear that sintering temperature with $55.36 \%$ has the most significant effect on densification of samples. Holding time with $24.24 \%$ and pressure with $17.05 \%$ follows the sintering temperature. Lastly heating rate with $2.78 \%$ has the least influence.

Transparency of polycrystalline ceramics strongly depends on its density. The porosity in the bulk ceramic causes light scattering which reduces transmission amount [3]. Due to this reason denser samples show higher transparency as expected. The most translucent ceramic produced by experiment 12 is the same as the densest one. However, achieving high density is not enough to obtain high transmission by itself. The amount of secondary phases, their structure and distribution in the microstructure, grain size/size distribution and shape of ceramic are also important factors [7]. 
TABLE II

Taguchi table of experimental design and results of density and transmission measurements.

\begin{tabular}{c|c|c|c|c|c|c|c}
\hline \hline $\begin{array}{c}\text { Exp. } \\
\text { no. }\end{array}$ & $\begin{array}{c}\text { Taguchi } \\
\text { L'16 array }\end{array}$ & $\begin{array}{c}\text { Sintering } \\
\text { temp. } \\
{\left[{ }^{\circ} \mathrm{C}\right]}\end{array}$ & $\begin{array}{c}\text { Pressure } \\
{[\mathrm{kN}]}\end{array}$ & $\begin{array}{c}\text { Holding } \\
\text { time } \\
{[\mathrm{min}]}\end{array}$ & $\begin{array}{c}\text { Heating } \\
\text { rate } \\
{\left[{ }^{\circ} \mathrm{C} / \mathrm{min}\right]}\end{array}$ & $\begin{array}{c}\text { Density } \\
{\left[\mathrm{g} / \mathrm{cm}^{3}\right]}\end{array}$ & $\begin{array}{c}\text { Transmission } \\
{[\%]}\end{array}$ \\
\hline 1 & $A_{1} B_{1} C_{1} D_{1}$ & 1650 & 5 & 0.5 & 50 & 2.3247 & 6 \\
2 & $A_{1} B_{2} C_{2} D_{2}$ & 1650 & 10 & 1.5 & 100 & 2.9228 & 3 \\
3 & $A_{1} B_{3} C_{3} D_{3}$ & 1650 & 15 & 2.5 & 200 & 2.7869 & 4 \\
4 & $A_{1} B_{4} C_{4} D_{4}$ & 1650 & 20 & 3.5 & 300 & 3.5293 & 38 \\
5 & $A_{2} B_{1} C_{2} D_{3}$ & 1750 & 5 & 1.5 & 200 & 3.2463 & 1.4 \\
6 & $A_{2} B_{2} C_{1} D_{4}$ & 1750 & 10 & 0.5 & 300 & 2.8161 & 2 \\
7 & $A_{2} B_{3} C_{4} D_{1}$ & 1750 & 15 & 3.5 & 50 & 3.5357 & 38 \\
8 & $A_{2} B_{4} C_{3} D_{2}$ & 1750 & 20 & 2.5 & 100 & 3.5316 & 44.48 \\
9 & $A_{3} B_{1} C_{3} D_{4}$ & 1850 & 5 & 2.5 & 300 & 3.5267 & 48 \\
10 & $A_{3} B_{2} C_{4} D_{3}$ & 1850 & 10 & 3.5 & 200 & 3.5305 & 45.16 \\
11 & $A_{3} B_{3} C_{1} D_{2}$ & 1850 & 15 & 0.5 & 100 & 3.5190 & 46.28 \\
12 & $A_{3} B_{4} C_{2} D_{1}$ & 1850 & 20 & 1.5 & 50 & 3.5358 & 49.32 \\
13 & $A_{4} B_{1} C_{4} D_{2}$ & 1950 & 5 & 3.5 & 100 & 3.5315 & 38 \\
14 & $A_{4} B_{2} C_{3} D_{1}$ & 1950 & 10 & 2.5 & 50 & 3.5245 & 41 \\
15 & $A_{4} B_{3} C_{2} D_{4}$ & 1950 & 15 & 1.5 & 300 & 3.5269 & 48 \\
16 & $A_{4} B_{4} C_{1} D_{3}$ & 1950 & 20 & 0.5 & 200 & 3.5323 & 43
\end{tabular}

Analysis of variance (ANOVA) for density of sintered samples.

TABLE III

\begin{tabular}{c|c|c|c|c|c|c|c}
\hline \hline Factors & DF & Seq. $S S$ & Adj. $S S$ & Adj. $M S$ & $F$ & $P$ & $P[\%]$ \\
\hline sintering temperature & 3 & 1.08702 & 1.08702 & 0.36234 & 5.16 & 0.106 & 55.36 \\
pressure & 3 & 0.34464 & 0.34464 & 0.11488 & 1.64 & 0.348 & 17.5 \\
holding time & 3 & 0.47539 & 0.47539 & 0.15846 & 2.26 & 0.261 & 24.24 \\
heating rate & 3 & 0.05442 & 0.05442 & 0.01814 & 0.26 & 0.852 & 2.78 \\
error & 3 & 0.21077 & 0.21077 & 0.07026 & & & 0.12 \\
total & 15 & 2.17224 & & & & & 100 \\
\hline
\end{tabular}

DF: Degrees of freedom, Seq. SS: Sequential sum of squares, Adj. SS: Adjusted sum of square, Adj.

MS: Adjusted mean square, F: F-value, P: P-value

According to the overall transmission results given in Table II, not all fully dense samples show the same
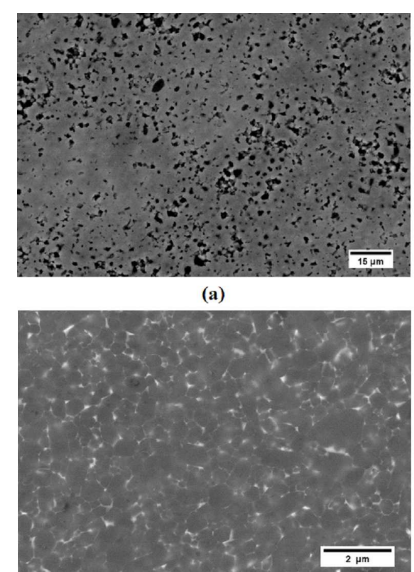

(c)

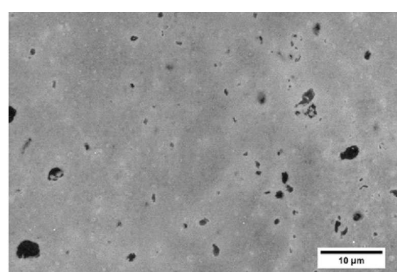

(b)

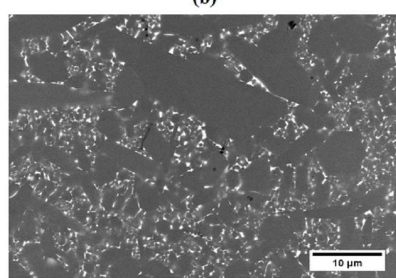

(d)
Fig. 1. SEM micrographs by back-scattering mode of (a) sample $1(2500 \times)$, (b) sample $3(5000 \times)$, (c) sample $12(30000 \times),(\mathrm{d})$ sample $13(5000 \times)$. amount of transmission. Higher than $11 \%$ transmission difference exists between sample 12 and other dense ones (for example experiments 4,7 , and 13). To understand reasons of these transmission differences, microstructural evolution of samples was examined by scanning electron microscopy. Some samples SEM images are given in Fig. 1. The SEM image of the sample fabricated by using $A_{1} B_{1} C_{1} D_{1}$ factor combination has spongy microstructure due to the high amount of porosity (Fig. 1a). A denser sample (experiment $3-A_{1} B_{3} C_{3} D_{3}$ ) microstructure is given in Fig. 1b. It is obviously shown that increase of applied pressure and holding time enhances the density of the ceramic. But, some amount of porosity still remains in the structure and grains cannot be seen so easily, due to the lack of grain boundaries. Two fully densified samples SEM images are given in Fig. 1c and d. Extreme grain growth is observed in sample 13 (Fig. 1d). This observation shows that experiment 13 sintering conditions so high for the composition. On the other hand, sample 12 has narrower and homogeneous grain size distribution than sample 13. Because of this reason the sample 
which is produced by experiment 13 shows in some way lower transmittance value than sample 12 .

The infrared transmittance of some specimens, ranging between 1000 and $4000 \mathrm{~cm}^{-1}$ are shown in Fig. 2. It is observed that the transmittance gradually increases with an increasing wave number in the range of around 2000 $2300 \mathrm{~cm}^{-1}$, and reaches maximum value. With further increase in wave number to beyond $2300 \mathrm{~cm}^{-1}$, the transmittance decreases through absorption.

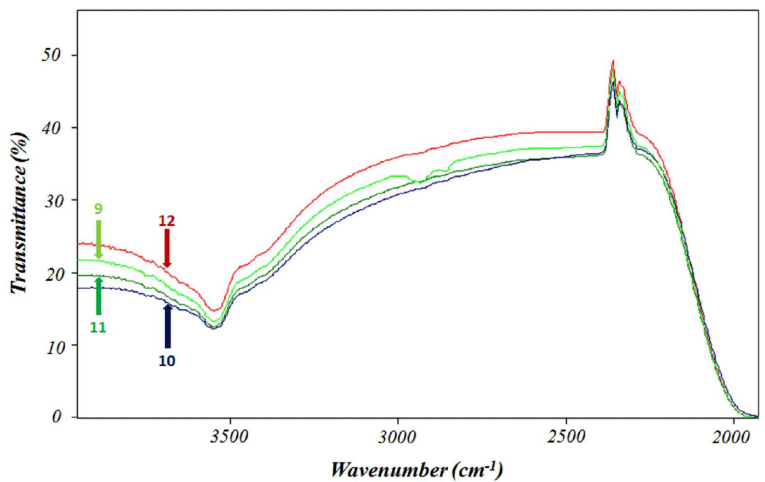

Fig. 2. Infrared transmission of SPS-ed specimens (sample 9, 10, 11 and 12).

The results of analysis of variance for maximum transmittance values of $0.3 \mathrm{~mm}$ thick samples are given in Table IV. Sintering temperature is most dominant factor to determine transparency of $\alpha$-SiAlON ceramics, the same as density. Unlike density ANOVA results, applied pressure is more effective than holding time for transparency.

TABLE IV

Analysis of variance (ANOVA) for transmittance of sintered samples.

\begin{tabular}{c|c|c|c|c|c|c|c}
\hline \hline Factors & DF & $\begin{array}{c}\text { Seq. } \\
S S\end{array}$ & $\begin{array}{c}\text { Adj. } \\
S S\end{array}$ & $\begin{array}{c}\text { Adj. } \\
M S\end{array}$ & $F$ & $P$ & $\begin{array}{c}P \\
{[\%]}\end{array}$ \\
\hline $\begin{array}{c}\text { sintering } \\
\text { temperature }\end{array}$ & 3 & 3273.0 & 3273.0 & 1091.0 & 9.36 & 0.049 & 60.3 \\
pressure & 3 & 1186.6 & 1186.6 & 395.5 & 2.42 & 0.171 & 21.8 \\
holding time & 3 & 657.1 & 657.1 & 219.0 & 1.88 & 0.309 & 12.2 \\
heating rate & 3 & 309.3 & 309.3 & 103.1 & 0.88 & 0.539 & 5.6 \\
error & 3 & 349.5 & 349.5 & 116.5 & & & 1.4 \\
total & 15 & 5775.5 & & & & & 100
\end{tabular}

The overall influence of design parameters on the transmission and density of the Dy-Y- $\alpha$-SiAlON samples was shown in Fig. 3. Increase of sintering temperature $1650^{\circ} \mathrm{C}$ to $1850{ }^{\circ} \mathrm{C}$ significantly improved both density and transparency of ceramics. However further rise $\left(1850\right.$ to $\left.1950^{\circ} \mathrm{C}\right)$ did not influence the density of the samples, additionally it negatively affected the transmittance of material. For pressure and holding time, higher values gave better results on density and transparency. On the contrary, changing heating rate did not cause any significant difference on density or transparency of products.

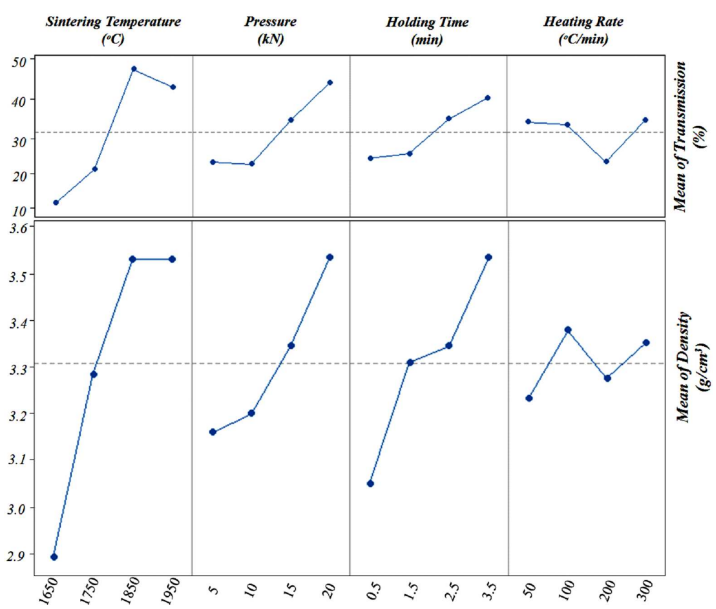

Fig. 3. Influence of design parameters on the transmission and density of the samples.

\section{Conclusion}

Translucent Dy-Y- $\alpha$-SiAlON ceramics with $m=2 n$ value were successfully prepared by SPS. According to the observations combination of the key factors: the uniform grain size with an equiaxed grain morphology, denser structure, and less grain boundary/secondary phases boosted the optical transmittance of the Dy-Y- $\alpha$ SiAlON ceramics. Taguchi L'16 orthogonal array was applied for the optimization of process parameters. Effects of the sintering temperature, pressure, holding time and heating rate on transparency and density of $\mathrm{Dy}-\mathrm{Y}-$ $\alpha$-SiAlON ceramics could be investigated by running just 16 experiments instead of 256. The results of ANOVA analysis for density and transparency show that most dominant production parameter is sintering temperature. Also holding time and pressure have strong influence as well.

\section{Acknowledgments}

This research has been supported by the Scientific and Technological Research Council of Turkey (TÜBİTAK), project number: $111 \mathrm{M} 427$.

\section{References}

[1] J. Sanghera, W. Kim, G. Villalobos, B. Shaw, C. Baker, J. Frantz, B. Sadowski, I. Aggarwal, Materials 5, 258 (2012).

[2] A. Krell, T. Hutzler, J. Klimke, J. Europ. Ceram. Soc. 29, 207221 (2009).

[3] H. Mandal, J. Europ. Ceram. Soc. 19, 2349 (1999).

[4] Y. Xiong, Z.Y. Fu, H. Wang, Y.C. Wang, J.Y. Zhang, Q.J. Zhang, Mater. Sci. Eng. A 488, 475481 (2008).

[5] H.M. Zhong, Q. Liu, J. Jiang, G.Y. Sun, Y. Luo, J. Appl. Phys. 106, 093514 (2009).

[6] X. Su, P. Wang, W. Chen, Y. Cheng, D. Yan, Mater. Lett. 58, 1985 (2004).

[7] S. Kurama, S. Avcioglu, E. Ayas, J. Europ. Ceram. Soc. 35, 3229 (2015). 